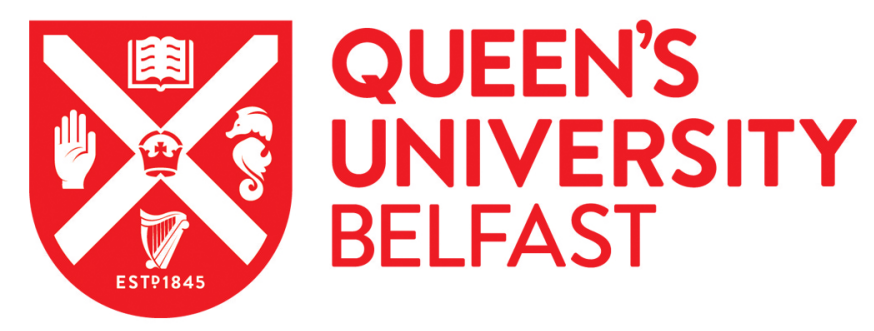

\title{
Current transients in the small salient-pole alternator caused by sudden short-circuit and synchronisation events
}

Best, R. J., Morrow, D. J., \& Crossley, P. A. (2010). Current transients in the small salient-pole alternator caused by sudden short-circuit and synchronisation events. IET Electric Power Applications, 4(9), 687-700. https://doi.org/10.1049/iet-epa.2009.0263

\section{Published in:}

IET Electric Power Applications

\section{Document Version:}

Peer reviewed version

Queen's University Belfast - Research Portal:

Link to publication record in Queen's University Belfast Research Portal

\section{Publisher rights}

Copyright 2010, The Institution of Engineering and Technology.

This work is made available online in accordance with the publisher's policies. Please refer to any applicable terms of use of the publisher.

\section{General rights}

Copyright for the publications made accessible via the Queen's University Belfast Research Portal is retained by the author(s) and / or other copyright owners and it is a condition of accessing these publications that users recognise and abide by the legal requirements associated with these rights.

Take down policy

The Research Portal is Queen's institutional repository that provides access to Queen's research output. Every effort has been made to ensure that content in the Research Portal does not infringe any person's rights, or applicable UK laws. If you discover content in the Research Portal that you believe breaches copyright or violates any law, please contact openaccess@qub.ac.uk. 


\title{
Current transients in the small salient-pole alternator during
}

\section{sudden short-circuit and synchronisation events}

Robert J. Best ${ }^{1}$, D. John Morrow ${ }^{1}$, Peter A. Crossley ${ }^{2}$

1 School of Electronic, Electrical Engineering and Computer Science, Queen's University Belfast, Belfast, BT9 5AH, UK, (Email: r.best@qub.ac.uk, dj.morrow@ee.qub.ac.uk)

2 The Joule Centre, The University of Manchester, Manchester, M60 1QD, UK, (Email: p.crossley@manchester.ac.uk)

\begin{abstract}
Small salient-pole machines, in the range $30 \mathrm{kVA}$ to $2 \mathrm{MVA}$, are often used in distributed generators, which in turn are likely to form the major constituent of power generation in power system islanding schemes, or microgrids. In addition to power system faults, such as short-circuits, islanding contains an inherent risk of out-of-synchronism re-closure onto the main power system. To understand more fully the effect of these phenomena on a small salient-pole alternator, the armature and field currents from tests conducted on a $31.5 \mathrm{kVA}$ machine are analysed. This paper demonstrates that by resolving the voltage difference between the machine terminals and bus into direct and quadrature axis components, interesting properties of the transient currents are revealed. The presence of saliency and short time-constants cause intriguing differences between machine events such as out-of-phase synchronisations and sudden three-phase short-circuits.
\end{abstract}

\section{$1 \quad$ Introduction}

The worldwide installed capacity of distributed generation is increasing and an interest in islanding of distribution networks $[1,2,3]$ has prompted the authors to review the out-of-phase synchronisation and fault characteristics of small alternators. Related work by the authors [4], concentrating on peak current and torque, has indicated that the synchronisation angle limits of salient-pole alternators could be increased 
significantly beyond the current narrow range of tolerances stipulated in IEEE 1547 [5] and ETR 113 [6]. This would be beneficial for schemes such as power system islanding and rapid generator start-up.

Some aspects of out-of-phase synchronisation have been identified, which in addition to being interesting from a machine theory perspective, may have practical significance for protection and machine equipment ratings. This paper provides an analysis of the armature and field winding transient currents observed during out-of-phase synchronisations and sudden short-circuits of a small alternator. The transients are referred to the classical two-reaction, $d q$-axis, machine theory $[7,8]$.

Adkins et al have generalised the machine theory so that it can be applied to any event that causes a sudden shift in $d$-axis or $q$-axis voltages [8,9]. In this paper, four armature current components, $D Q, Q Q$, $D D, Q D$, and two field current components $F D$ and $F Q$ will be identified and used for analysis. This allows the very peculiar currents observed during sudden three-phase short-circuit and synchronisation events to be understood in the context of the saliency and short time-constants that small salient-pole machines exhibit. A number of phenomena are investigated; the peak current difference between leading and lagging synchronisations of equal angle, different decay rates for events that experience equal shift in voltage magnitude, the peculiarities of sudden three-phase short-circuits on a loaded machine, and differences in field current transients.

\section{Current Components}

Many power system simulation tools employ a synchronous machine model based on two-reaction theory. The classical two-reaction machine equation $[8,10]$ describes the relationship of machine quantities referenced by the Park transformation $[7,11]$ to the rotating $d q$-axis frame. This leads to a number of $d$ - and $q$-axis parameters which must be known accurately in order to simulate the machine's transient performance. However, the determination of transient and sub-transient reactances in the small salient-pole machine is difficult due to short time-constants [12].

The sudden three-phase short-circuit of an unloaded machine is often used for parameter determination $[13,14]$. In this test a balanced step in voltage occurs along the $q$-axis in the armature winding, ' $v_{q}$ ', as shown in Fig. 1(a), and results in direct $(d)$ and quadrature $(q)$ axis currents which can be analysed. Similarly 
there are times when a balanced voltage shift can occur in both the $d$ - and $q$-axis simultaneously, ' $v_{d}$ ' and ' $v_{q}$ ', such as the sudden three-phase short-circuit of a loaded machine, Fig. 1(b), or the out-of-phase synchronisation of the machine onto the main power system Fig. 1(c), (d) and (e). The loaded short-circuit is a design constraint for larger synchronous machines [15], and out-of-phase synchronisations are of interest as they can be more severe for the machine than any other event $[4,16,17]$. Thus it is of benefit to understand the physical process during these events.

Fig. 2(a) shows the flux vectors following a sudden three-phase short-circuit of the unloaded machine, which has a voltage shift in the $q$-axis. The flux linking each winding, initially along the $d$-axis, cannot change immediately due to the theorem of constant flux. The effect of rotor rotation is to require an armature leakage flux that saturates the iron, so increasing magnetic path reluctance and lowering reactance. This results in an armature current which is mirrored in the rotor circuits according to the initial mutual flux linkages between each circuit pair $[8,11,18]$. Referring to Fig. 2(a), at $0^{\circ}$ rotation (and $360^{\circ}$ rotation) there is no armature leakage flux. The armature leakage flux magnitude in the $q$-axis direction reaches a maximum at $90^{\circ}$ rotation with another maximum at $270^{\circ}$ rotation. At $180^{\circ}$ rotation the armature leakage flux in the $d$-axis direction is at a maximum. This leads to $q$-axis, $d$-axis and resultant leakage flux profiles as indicated by Fig. 2(b). The $d$-axis flux is transformed to current by the $d$-axis reactance, and $q$-axis flux by the $q$-axis reactance. It follows that the $d$-axis current component will exhibit a $1-\cos (\omega t)$ characteristic, and the $q$-axis current will exhibit a $\sin (\omega t)$ characteristic. The loss of stored magnetic energy, and thus the decay of trapped flux, causes reactance to rise towards the steady-state value and the currents to decrease. The rate of decay is particularly fast in small machines due to high per unit resistances, and can mean that even by the time of the expected peak leakage flux at $180^{\circ}$ rotation in Fig. $2(\mathrm{~b}),(\approx 0.01 \mathrm{~s}$ with a pre-event frequency of $50 \mathrm{~Hz}$ ) significant reduction in the trapped flux has already occurred and armature currents are much lower than the theory of constant flux linkages would suggest. The high torques associated with high current can significantly change the speed of the machine, also affecting the time that the peak currents occur. Field current will tend to mirror the $d$-axis current, except for the effect of unequal mutual flux linkages between damper, field and armature circuits $[19,20]$.

In an event where the voltage shift occurs in the $d$-axis, such as in fig. 1(e) for a lagging synchronisation with a load angle half that of the synchronisation angle, the major difference is that the flux 
components originate on the $q$-axis. Thus, and by ignoring the decay of flux, the $d$-axis current is characterised by $\sin (\omega t)$, and $q$-axis is characterised by $1-\cos (\omega t)$.

Four components of transient armature current can now be identified. These components are:

- $\quad D Q \quad d$-axis armature current due to $q$-axis armature voltage shift

- $Q Q \quad q$-axis armature current due to $q$-axis armature voltage shift

- $\quad D D \quad d$-axis armature current due to $d$-axis armature voltage shift

- $Q D \quad q$-axis armature current due to $d$-axis armature voltage shift

Two similar current components exist for the field winding, due to the field winding's physical location on the $d$-axis.

- FQ Field current due to $q$-axis armature voltage shift

- $\quad F D \quad$ Field current due to $d$-axis armature voltage shift

Although the fundamental frequency, either $1-\cos (\omega t)$ or $\sin (\omega t)$, is dominant in the four armature current components, there are a number of other factors: different circuit resistances cause the trapped flux to decay at different rates in armature and rotor circuits; the presence of sub-transient saliency causes the induced currents themselves to have an effect on the flux and reluctances, resulting in a double-fundamental frequency current; harmonic currents are also present in the windings.

Equation (1) contains the four current components $D Q, Q Q, D D$, and $Q D$. It is obtained from the classical machine equation by assuming that the voltage shift only occurs in the armature and that there is no step in the field voltage. The machine equations and definition of the four armature current components are given in the Appendix.

$\left[\begin{array}{l}i_{d}{ }^{\prime} \\ i_{q^{\prime}}{ }^{\prime}\end{array}\right]=\left[\begin{array}{cc}-D D & -D Q \\ Q D & -Q Q\end{array}\right]\left[\begin{array}{l}v_{d}{ }^{\prime} \\ v_{q}{ }^{\prime}\end{array}\right]$

The initial load current components, $i_{d 0}$ and $i_{q 0}$, often small in comparison to transient currents, are added to the transient current to give total current as in equation (2). 
$\left[\begin{array}{l}i_{d} \\ i_{q}\end{array}\right]=\left[\begin{array}{l}i_{d 0}+i_{d}{ }^{\prime} \\ i_{q 0}+i_{q}{ }^{\prime}\end{array}\right]$

In the Appendix, simplified time domain expressions for $D Q, D D, Q Q$ and $Q D$ armature currents (13), (14), (15), (16), and $F Q(18)$ and $F D$ (19) field currents are presented. They confirm the fundamental frequency characteristic of Fig. 2, and also give an indication as to which decay time-constants and transient or sub-transient, $d$ - and $q$-axis reactances have largest bearing on each current component. These dominant characteristics are summarised in Table 1.

Table 1 Characteristics of the armature and field current components.

\begin{tabular}{|l|l|l|l|}
\hline Current Component & Characteristic & Magnitude & Decay \\
\hline$D Q$ & $1-\cos (\omega t)$ & $X_{d}{ }^{\prime \prime}, X_{d}{ }^{\prime}$ & $\tau_{d}{ }^{\prime}, \tau_{d}{ }^{\prime \prime}, \tau_{a}$ \\
\hline$Q Q$ & $\sin (\omega t)$ & $X_{q}{ }^{\prime \prime}$ & $\tau_{a}$ \\
\hline$D D$ & $\sin (\omega t)$ & $X_{d}{ }^{\prime \prime}$ & $\tau_{a}$ \\
\hline$Q D$ & $1-\cos (\omega t)$ & $X_{q}{ }^{\prime \prime}$ & $\tau_{q}{ }^{\prime \prime}, \tau_{a}$ \\
\hline$F Q$ & $1-\cos (\omega t)$ & $X_{d}{ }^{\prime},\left(\tau_{k d} / \tau_{d}{ }^{\prime}\right)$ & $\tau_{d}{ }^{\prime}, \tau_{a},\left(\tau_{d}{ }^{\prime}\right)$ \\
\hline$F D$ & $\sin (\omega t)$ & $X_{d}{ }^{\prime},\left(\tau_{k d} / \tau_{d}{ }^{\prime \prime}\right)$ & $\tau_{a}$ \\
\hline
\end{tabular}

\section{Experimental Procedure}

\subsection{Experimental Test-Bed}

A 4-pole, salient pole synchronous machine, rated at $31.5 \mathrm{kVA}$ and 0.8 power factor is used for experimentation as shown in Fig. 3. The synchronous machine parameters as provided in the device's datasheet are shown in Table 2. A brushless excitation system is used to supply the main field current, as is common in machines of this size. The alternator is capable of being suddenly short-circuited or synchronised out-of-phase to the mains $415 \mathrm{~V}$ power supply at the University through a three-phase contactor. The synchronous machine is coupled through a compressed rubber coupling to a vector controlled induction machine, which, prior to the tests, can be held at any desired speed and angle relative to the mains by an A.C. drive. Voltage and current are measured by Hall Effect transducers using a 6025E National Instruments data acquisition card, with data being captured by a Mathworks xPC target xPC at 32 samples / cycle. The brushless excitation system means that there is no method of measuring field current in the manufacturer's standard product, thus slip-rings were added to make this possible. This extra resistance will have a minor effect on the observed transients. The pulses from a 1000 line rotary encoder on the vector controlled 
induction machine are captured by the data acquisition card's counter function to give an indication of speed and rotor position, thus allowing the $d$ - and $q$-axes to be confidently and accurately determined during the transient.

Table 2 Datasheet parameters of $31.5 \mathrm{kVA}$ alternator, $400 \mathrm{~V}$ base

\begin{tabular}{|c|c|c|}
\hline Parameter & Symbol & Value \\
\hline$d$-axis reactance & $X_{d}$ & 2.2 \\
\hline$q$-axis reactance & $X_{q}$ & 1.1 \\
\hline$d$-axis transient reactance & $X_{d^{\prime}}$ & 0.118 \\
\hline$d$-axis sub-transient reactance & $X_{d^{\prime}}{ }^{\prime}$ & 0.059 \\
\hline$q$-axis sub-transient reactance & $X_{q}{ }^{\prime}$ & 0.084 \\
\hline$d$-axis transient time-constant & $\tau_{d^{\prime}}$ & 0.030 \\
\hline$d$-axis sub-transient time-constant & $\tau_{d^{\prime}}{ }^{\prime}$ & 0.003 \\
\hline armature time-constant & $\tau_{a}$ & 0.004 \\
\hline
\end{tabular}

\section{2 $D$-axis and $Q$-axis Armature Current Identification}

The peak resultant armature current during three-phase events at the machine terminals can be described with relation to equation (1) and (2). Ignoring the load current components, $i_{d 0}$ and $i_{q 0}$, which are often small compared to the peak current, the resultant armature current comprises the four components $D Q$, $D D, Q Q$ and $Q D$.

The armature phase currents measured from experimental tests can be referenced to the rotor as $d$-axis and $q$-axis components by applying the Park transform (3), [7, 11].

$$
\left[\begin{array}{l}
i_{d} \\
i_{q} \\
i_{0}
\end{array}\right]=\frac{2}{3}\left[\begin{array}{ccc}
\cos \theta & \cos \left(\theta-120^{\circ}\right) & \cos \left(\theta+120^{\circ}\right) \\
-\sin \theta & -\sin \left(\theta-120^{\circ}\right) & -\sin \left(\theta+120^{\circ}\right) \\
\frac{1}{2} & \frac{1}{2} & \frac{1}{2}
\end{array}\right]\left[\begin{array}{l}
i_{a} \\
i_{b} \\
i_{c}
\end{array}\right]
$$

The point of short-circuit or synchronisation in the cycle of the $a$-phase is noted as angle $\lambda_{0}$. This can be determined accurately in the unloaded machine as the angle which gives maximum pre-event $q$-axis voltage, and zero $d$-axis voltage. Load angle must be included for the loaded machine. In the experimental arrangement, a rotary encoder provides the relative rotor position $\lambda_{(t)}$, as the alternator frequency changes 
significantly during the synchronisation, due to high torque. The angle $\left(\lambda_{0}+\lambda_{(t)}\right)$ replaces $\theta$ in the Park transform (3) to calculate the $d$-axis and $q$-axis current components at each sampled point.

The zero-sequence current component was calculated and found to be negligible, confirming the symmetry of these tests.

\section{Sudden Short-Circuit Analysis}

With reference to (1) and Fig. 1(a), consider the sudden three-phase short-circuit of the unloaded machine which has a voltage shift of $v_{q}=-1.0 \mathrm{pu}$, and $v_{d}=0.0 \mathrm{pu}$. In this case, only the $D Q$ and $Q Q$ components of armature current are present. By ignoring decay and change in speed, the peak resultant armature current will occur when the rotor has rotated $180^{\circ}$ following the event, as shown in Fig. 2(a) (0.01 seconds in a $50 \mathrm{~Hz}$ system). This coincides with the point when maximum armature winding leakage flux is required to maintain the flux linking the armature winding, under the theorem of constant flux linkages.

The components $D Q$ and $Q Q$ can clearly be seen as the $d$-axis and $q$-axis armature currents in Fig. 4(b) for a sudden three-phase short-circuit of the unloaded $31.5 \mathrm{kVA}$ test alternator at $415 \mathrm{~V}$. For comparison, Fig. 4(a) shows the three phase currents. Component $D Q$ resembles a $1-\cos (\omega t)$ function, which peaks at approximately 0.01 seconds $\left(180^{\circ}\right)$ and is then dominated by the unidirectional decay of the transient time period, that is $t_{d}{ }^{\prime}$. Again as expected, component $Q Q$ resembles a rapidly decaying sinusoid, peaking at $90^{\circ}$ rotor rotation.

This $d q$-axis current decomposition technique has been used successfully for parameter determination following sudden short-circuits of unloaded synchronous machines [12].

\subsection{Sudden Three-Phase Short-Circuit of a Loaded Machine}

The sudden short-circuit of a loaded machine is more complex as both components of $v_{q}$ and $v_{d}$ voltage shift exist, as shown in Fig. 1(b).

A $25 \mathrm{~kW}$ load is used to achieve a load angle of $38^{\circ}$ at $415 \mathrm{~V}$ when the sudden three-phase shortcircuit is applied. This event has voltage shifts of $v_{q}=-0.788$ and $v_{d}=-0.616$. The components $D Q, D D, Q Q$ 
and $Q D$ can be extracted by using the $D Q$ and $Q Q$ components from the unloaded sudden short-circuit test in Fig. 4(b) and substituting them into (1). The loaded and unloaded sudden three-phase short-circuits result in different mechanical transients, and so the accuracy of this method decreases with time. However, over the first two or three cycles, useful interpretations can be made. The four components are plotted in Fig. 5, and it can be observed that each component resembles the characteristics from Table 1. Fig. 5 can be used to help explain some of the differences between unloaded and loaded sudden three-phase short-circuits.

In small salient-pole alternators, the sub-transient reactance is lower in the $d$-axis direction, $X_{d}{ }^{\prime \prime}<X_{q}{ }^{\prime \prime}$, see Table 2, and so components $D Q$ and $D D$ tend to have higher amplitudes than their $Q Q$ and $Q D$ counterparts. Additionally, since the $v_{q}$ shift is larger than $v_{d}$ in this event, $D Q$ is the dominant component.

In this event, the $v_{q}$ and $v_{d}$ shifts were both negative, and implies that the $D D$ component initially acts in the same direction as the $D Q$ component. $Q D$ is the only component not accompanied by a negative sign in (1), and initially opposes $Q Q$ because the $v_{d}$ shift is negative. Combined with the lower $d$-axis subtransient reactance, the net result is that the peak current occurs slightly earlier in the loaded short-circuit than the unloaded case. This may be observed in the resultant armature current plots in Fig. 6(a), where the time difference between the peak currents is in the order of $1.25 \mathrm{~ms}$.

The field current also peaks earlier in the loaded short-circuit as there is a component $F D$ in addition to $F Q$, which resemble $D D$ and $D Q$ of Fig. 5(a). Again due to negative $v_{d}$ shift, component $F D$ causes the field current to peak earlier in the loaded sudden three-phase short-circuit, as observed in Fig. 6(b).

The sign of $v_{d}$ shift can affect the transient current by inverting the components $D D$ and $Q D$. For example, it would be expected that a generating (loaded) alternator with a negative $v_{d}$ shift would have a higher and earlier peak current than a motoring alternator with an equal but positive $v_{d}$ shift. The effect of the $v_{d}$ shift's sign is explained later when comparing leading and lagging synchronisations.

Additionally, there is a difference between events which have the same resultant voltage shift, i.e. trap the same amount of flux. This is caused by the ratio of $v_{d}$ and $v_{q}$ voltage shift, which can affect the magnitude of peak current and its rate of decay. 
$D Q$ is the armature current component most affected by the slowly decaying trapped flux in the field winding, characterised by the $d$-axis transient time-constant $t_{d}$, see Table 1 , and in the Appendix compare (13) with (14), (15) and (16). Thus, events with larger $v_{q}$ shift should exhibit slower decay rates than those with larger $v_{d}$ shift. Although less noticeable, both Fig. 6(a) and Fig. 6(b) indicate that the loaded alternator's current decays more rapidly.

The earlier peak current of the loaded sudden short-circuit would suggest that the trapped flux has decayed less by this time, leading to higher saturation and peak current. However, the larger $v_{d}$ shift means more of the trapped flux acts across the lower sub-transient reluctance of the $q$-axis. It appears that in this case these effects cancel out, and the magnitude of resultant armature current of the short-circuits in Fig. 6(a) is similar.

\section{Out-of-Phase Synchronisation Current Analysis}

\subsection{Armature Current Components of an Out-of-Phase Synchronisation}

During out-of-phase synchronisation, components of $v_{q}$ and $v_{d}$ voltage shift often occur. By way of explanation, leading and lagging synchronisations at $60^{\circ}$ are used. The $60^{\circ}$ synchronisations of an unloaded machine onto a bus of equal voltage magnitude have a voltage shift of $v_{q}=-0.5 \mathrm{pu}$ and $v_{d}=-0.866 \mathrm{pu}$ when lagging, see Fig. 1(c), and $v_{q}=-0.5$ pu and $v_{d}=+0.866$ pu when leading, see Fig. 1(d). Additionally, these $60^{\circ}$ synchronisations have a resultant voltage shift magnitude of $1.0 \mathrm{pu}$, the same as the sudden three-phase short-circuits in the previous section.

To resolve this event which contains all four components, the sign difference of $v_{d}$ shift between leading and lagging synchronisations can be exploited by using simultaneous equation substitution in (1) to give the components $D Q, D D, Q Q$ and $Q D$.

The experimental tests were conducted with minimal error in grid and alternator voltage magnitude and synchronisation angle. It should be noted that the differing mechanical transients have a bearing on the accuracy of this method, more so than for the sudden short-circuit. The rotor accelerates following a lagging synchronisation, and retards following a leading synchronisation [4]. However, over the first cycle or so, at least some indication of the individual components is attained. 
Synchronisation involves a system impedance, that is largely resistive at this voltage level, reducing the peak current and causing current to decay faster [21]. Furthermore, as the rotor moves to reduce the angle with the main power system the potential synchronising current is reduced. Generally, this shortens the length of the current transient. However, if the alternator oscillates against the grid during the synchronisation process, the length of current transients may be extended.

The four components from $60^{\circ}$ synchronisations on a $31.5 \mathrm{kVA}$ alternator are shown in Fig. 7, where $D D$ and $Q D$ are presented with a lagging synchronisation orientation, i.e. for negative $v_{d}$ shift. Since $X_{d}{ }^{\prime \prime}<X_{q}{ }^{\prime \prime}$ and as the $v_{d}$ shift is larger than the $v_{q}$ shift in this $60^{\circ}$ synchronisation, it is component $D D$ which has the greatest bearing on the sub-transient current. The effect that this has on peak resultant armature current between leading and lagging synchronisations will be discussed.

\subsection{Peak Resultant Armature Current}

In an ideal large cylindrical machine, characterised by long time constants and $X_{d}{ }^{\prime \prime}=X_{q}{ }^{\prime \prime}$, the resultant of (1) will be the same for leading and lagging synchronisations, with peak current occurring at $180^{\circ}$ rotor rotation, despite the sign change of $v_{d}$ between Fig. 1(c) and (d).

When a machine exhibits saliency, but still has long time constants, peak current does not necessarily occur at $180^{\circ}$ rotor rotation. As the $v_{q}$ shift is negative in these synchronisation events, $D Q$ gives positive peak current at $180^{\circ}$ rotation, while the sizeable term $D D$ has a positive peak at $270^{\circ}$ rotation when $v_{d}$ shift is positive, such as in a rotor leading synchronisation, placing the resultant peak current at a rotation greater than $180^{\circ}$. This is shown in Fig. 8 (a) for the $60^{\circ}$ synchronisation of a machine with an $X_{d}^{\prime \prime} / X_{q}^{\prime \prime}$ ratio of 0.7. For negative $v_{d}$ shift, that is a rotor lagging synchronisation, term $D D$ has a maxima at $90^{\circ}$, and so the resultant peak current will occur before $180^{\circ}$ rotation, as indicated in Fig. 8(a). Thus, when ignoring decay, the peak armature current would be expected to occur before $180^{\circ}$ rotation for rotor lagging synchronisations and after $180^{\circ}$ rotation for rotor leading synchronisations.

In small salient-pole machines the effect of decay on the current components is very significant and cannot be neglected. As a result, the peak resultant armature current occurs before $180^{\circ}$, or 0.01 seconds, for both leading and lagging synchronisations, as indicated in the simulation plot Fig. 8(b) and the experimental 
result Fig. 8(c). Notably, the magnitude of the armature current observed in the leading case is less than that in the lagging case. This effect is considerable in small salient-pole alternators, and in the test machine the $60^{\circ}$ lagging synchronisation peak current is approximately $30 \%$ higher than the $60^{\circ}$ leading synchronisation peak current.

\subsection{Field Current Transient}

The transient field current observed during out-of-phase synchronisations is interesting. The plots in Fig. 9 show the field current transients for $60^{\circ}$ leading and lagging synchronisations. It is noticeable that the field current becomes negative for a period during both synchronisations, this is evidence that either the diode bridge or varistor in the machine's brushless excitation system has broken down.

There is significant difference between the two field current transients. In the $60^{\circ}$ synchronisation, the large $v_{d}$ shift causes $F D$ to dominate the peak field current, in a similar manner to $D D$ on the armature current. When $F D$ and $F Q$ initially act in the same direction in the $60^{\circ}$ lagging synchronisation the peak field current occurs between 5 and $10 \mathrm{~ms}$. The two components initially act in opposite directions in the $60^{\circ}$ leading synchronisation, and this causes an initially negative field current. The ratio of the $v_{d}$ and $v_{q}$ shifts and the retardation caused by leading synchronisation cause a positive peak field current to occur close to $15 \mathrm{~ms}$. In this machine, during a lagging synchronisation the peak field current is significantly larger than when leading.

\section{Other Three-Phase Events}

\subsection{Event with only $v_{d}$ shift}

It was noted that the short-circuit of an unloaded machine contains only a $v_{q}$ shift, and thus only $D Q$ and $Q Q$ components. However, it is more difficult to obtain an event that has only a $v_{d}$ shift. One example is the synchronisation of a lagging alternator with a load angle that is half of the synchronising angle, shown in Fig. 1(e). In this case, only a $v_{d}$ shift occurs, with $D D$ and $Q D$ components.

As an example, a lagging synchronisation at $50^{\circ}$ with a load angle of $22.5^{\circ},\left(v_{d}=-0.84\right.$, with a negligible $\left.-v_{q}=0.04\right)$ is performed. The $d$-axis, $q$-axis and field current representing $D D, Q D$ and $F D$ respectively are plotted in Fig. 10(a) and (b). 
As expected, the $v_{d}$ shift components of the synchronisation in Fig. 10 correlate to both Table 1 and the components previously extracted from the other events. The field and $d$-axis current ( $F D$ and $D D$ ) peak at around $5 \mathrm{~ms}$ and exhibit $\sin (\omega t)$, whereas the $Q D$ resembles $-1+\cos (\omega t)$ and peaks slightly before 0.01 seconds. It is interesting to note that peak $D D$ is higher than the peak $Q Q$ of Fig. 4(b) for the sudden short-circuit, even though the short-circuit resultant voltage shift is $1.0 \mathrm{pu}$. This is due to sub-transient saliency, where $X_{d}^{\prime \prime}<X_{q}^{\prime \prime}$.

\subsection{Event with positive $v_{q}$ shift}

It is possible to create an event with a positive $v_{q}$ shift, for example, a synchronisation at $0^{\circ}$ while the alternator is under-excited. The result for a synchronisation at 0.8 per unit $\left(v_{q}=+0.2 \mathrm{pu}\right)$ is shown in Fig. 11 . Negative field and $d$-axis currents result, and the $q$-axis current has a $-\sin (\omega t)$ profile. Thus, the current transient is the reverse of an unloaded sudden three-phase short-circuit, see Fig. 4(b). Once synchronised, the alternator continues to draw an excitation current from the grid.

\subsection{Event with positive $v_{q}$ shift and negative $v_{d}$ shift}

The transient currents from more peculiar events can also be explained using axis voltage shift. Consider the lagging synchronisation of a loaded, under-excited alternator onto the main system. If the synchronisation angle is $50^{\circ}$, the load angle $22.5^{\circ}$ and the terminal voltage 0.55 per unit, then voltage shifts of $v_{q}=+0.38 \mathrm{pu}$ and $v_{d}=-0.67 \mathrm{pu}$ occur. The combination of negative $v_{d}$ and positive $v_{q}$ shift will produce a transient unlike those previously analysed. The $d$-axis and field current would be expected to have a large $+\sin (\omega t)$ with a significant $-1+\cos (\omega t)$ component, and this can be observed in the result of Fig. 12 . The $q$-axis current will be largely $-1+\cos (\omega t)$, but with significant $-\sin (\omega t)$.

Interestingly, the transient currents from this event should appear as a reflection of a $60^{\circ}$ leading synchronisation. Although a $60^{\circ}$ leading synchronisation has a larger magnitude of voltage shift, it has a similar ratio of $v_{d}$ to $v_{q}$, while the $v_{d}$ shift is positive and $v_{q}$ shift is negative. This effect is quite striking when the field current of Fig. 12(b) is compared with that with that in Fig. 9. 


\subsection{Simulation of Small Salient-Pole Machines}

Machines are often described in power system simulation packages by the classical $d q$-model. The machine equation uses an exponentially based approximation for changing reactance, thus assuming an exponential decay of stored magnetic energy. In reality, the stored energy can only be dissipated when current flows in the windings.

The effect of this assumption is minimal for large machines. However, this is not the case for small salient-pole machines due to the rapid decay of stored energy. This paper has shown that the current transients observed during the first cycle are event specific. Parameters are often determined from sudden short-circuits of unloaded machines and so similar events are described reasonably well. If parameters were determined from the loaded short-circuit in Fig. 5 using the method in [12], it would be expected that larger sub-transient reactances, or longer sub-transient time constants, than those of the unloaded short-circuit would be obtained. The exponential approximation implies that even if the classical machine model correctly predicts peak current, it will not accurately predict current before the first peak ( $10 \mathrm{~ms})$, leading to a faster rise in predicted current than that observed in practice. Thus, parameters are event specific and, for small machines in particular, the inaccuracy of representation by the classical machine model merits further investigation.

\section{Conclusion}

Knowing the magnitude, sign and ratio of the $d$-axis and $q$-axis armature voltage shifts that initiate a three-phase event can reveal much about the current transient, even without a rigorous mathematical analysis. This is particularly useful in small alternators, typically used in distributed generation, where conventionally determined parameters may be unreliable and event specific.

Classical $d q$-theory suggests that four armature current, and two field current, components can be identified and used to analyse winding currents during machine events. These current components have been extracted from a number of symmetrical events on a $31.5 \mathrm{kVA}$ alternator, and have effectively demonstrated some of the peculiarities of the armature and field current during the first few cycles. 
A loaded sudden three-phase short-circuit has an earlier peak armature and field current than its unloaded counterpart. This is due to sub-transient saliency and the characteristics of the current components.

Component $D D$, the $d$-axis armature current due to $d$-axis voltage shift, is largely responsible for the peak resultant armature current being smaller during leading angle out-of-phase synchronisations than during lagging synchronisations at equivalent angle. Furthermore, during events where the $d$-axis voltage shift is large in comparison with the $q$-axis voltage shift, the peak resultant armature current tends to be lower and decays at a faster rate.

When applied to the field current, the component due to $d$-axis voltage shift, $F D$, explains why the field current initially rises in a lagging synchronisation, while initially falling and often causing negative field current in a leading synchronisation of equivalent angle.

Similarly, other events can be explained, such as the synchronisation of an under-excited alternator that exhibits only a positive $q$-axis voltage shift, and synchronisation of a loaded alternator with a synchronisation angle twice that of the load angle, which has only a $d$-axis voltage shift.

This paper has shown that the short-circuit and synchronisation current transients observed during the first cycle are event specific. It follows that not all events in small salient-pole alternators can be described accurately by the classical machine model when using parameters determined from the three-phase short circuit of an unloaded machine.

\section{Acknowledgements}

This work is funded through the EPSRC Supergen V, UK Energy Infra-structure (AMPerES) grant in collaboration with UK electricity network op-erators working under Ofgem's Innovation Funding Incentive scheme; full details on http://www.supergen-amperes.org.

\section{References}

[1] Hatziargyriou, N., Asano, H., Iravani, R., and Marnay, C.: 'Microgrids: an overview of ongoing research, development and demonstration projects', IEEE Power \& Energy Mag., 5, (4), pp. 78 - 94, Jul. Aug. 2007 
[2] Lund, P.: 'The Danish cell project - part 1: background and general approach', IEEE Power Eng. Soc. General Meeting, Tampa Bay, USA, pp. 1 -6, Jun. 2007

[3] Best, R. J., Morrow, D. J., McGowan, D. J., and Crossley, P. A.: 'Synchronous islanded operation of a diesel generator’, IEEE Trans. Power Syst., 22, (4), pp. 2170 - 2176, Nov. 2007

[4] Best, R .J., Morrow, D. J., and Crossley, P. A.: 'Effect of loading, voltage difference and phase angle on the synchronisation of a small alternator', IET Electr. Power Appl., 3, (6), pp. 531-542, Nov. 2009

[5] IEEE Standard 1547-2003: 'IEEE standard for interconnecting distributed resources with electric power systems', 2003.

[6] UK Electricity Association, 'Engineering Technical Report (ETR) No. 113: Notes of guidance for the protection of embedded generating plant up to $5 \mathrm{MW}$ for operation in parallel with public electricity suppliers' distribution system', 1995

[7] Park, R. H.: 'Two-reaction theory of synchronous machines, generalized method of analysis Part 1', Trans. AIEE, 1929, 48, pp. 716730

[8] Adkins, B., and Harley, R G.: 'The general theory of alternating current machines: application to practical problems', (Chapman and Hall, London, 1975)

[9] Adkins, B.: 'Transient theory of synchronous generators connected to power systems', Proc. IEE, 1951, 98, (64), pp. 510-528

[10] Krause, P. C., Wasynczuk, O, and Sudhoff, S. D.: 'Analysis of electric machinery and drive systems', (IEEE Press - John Wiley \& Sons, Piscataway, 2002, 2nd edn.)

[11] Fitzgerald, A. E., Kingsley, C., and Umans, S. D.: 'Electric Machinery', (McGraw - Hill, London, 1992, 5th edn. in SI units)

[12] Martin, J.P., Tindall, C.E., and Morrow, D.J.: 'Synchronous machine parameter determination using the sudden short-circuit axis currents', IEEE Trans. Energy Convers., 1999, 14, (3), pp. $454-459$

[13] BS EN 60034-4:1995: 'Rotating electrical machines: part4. methods for determining synchronous machine quantities from tests'

[14] IEEE Standard 115-1995: 'IEEE guide: test procedures for synchronous machines', 1995

[15] IEEE Standard C50.13-2005: 'IEEE standard for cylindrical-rotor $50 \mathrm{~Hz}$ and $60 \mathrm{~Hz}$ synchronous generators rated 10 MVA and above', 2005 
[16] Wood, A. J.: 'Synchronizing out of phase', Trans. AIEE, Part III (Power App. and Syst.), 1957, 76, (29), pp. 1-8

[17] Canay, M.: 'Stresses in turbogenerator sets due to electrical disturbances', Brown Boveri Review, September 1975, 62, (9), pp. $435-443$

[18] Say, M. G.: 'Alternating Current Machines', (Longman Science and Technical, Harlow, 1992, 5th edn.)

[19] Canay, I.M.: 'Causes of discrepancies on calculation of rotor quantities and exact equivalent diagrams of the synchronous machine', IEEE Transactions on Power Apparatus and Systems, July 1969, PAS-88, (7), pp. $1114-1120$

[20] Takeda, Y., and Adkins, B.: 'Determination of synchronous machine parameters allowing for unequal mutual inductances', Proc. IEE, December 1974, 121, (12), pp. 1501 - 1504

[21] Kirschbaum, H. S.: 'Transient electrical torques of turbine generators during short circuits and synchronizing', Trans. AIEE, 1945, 64, pp. 65-70

[22] Kamwa, I., Pilote, M., Carle, H., Viarouge, P., Mpanda-Mabwe, B., Crappe, M., 'Computer software to automate the graphical analysis of sudden short-circuit oscillograms of large synchronous machines', IEEE Trans. Energy Convers., 1995, 10, (3), pp. 399-406

\section{Appendix}

Classical machine equation in operational impedance form, (4), assuming no shift occurs in field voltage, $v_{f},[9,10]$ :

$\left[\begin{array}{l}v_{d}{ }^{\prime} / p \\ v_{q}{ }^{\prime} / p\end{array}\right]=\left[\begin{array}{cc}-\left(R_{a}+p X_{d}(p) / \omega\right) & X_{q}(p) \\ -X_{d}(p) & -\left(R_{a}+p X_{q}(p) / \omega\right)\end{array}\right]\left[\begin{array}{l}i_{d}{ }^{\prime} \\ i_{q^{\prime}}\end{array}\right]$

The operational impedances are

$$
\begin{aligned}
& X_{d}(p)=\frac{\left(1+\tau_{d}{ }^{\prime} p\right)\left(1+\tau_{d}{ }^{\prime \prime} p\right)}{\left(1+\tau_{d o}{ }^{\prime} p\right)\left(1+\tau_{d o}{ }^{\prime \prime} p\right)} X_{d} \\
& X_{q}(p)=\frac{\left(1+\tau_{q}{ }^{\prime} p\right)}{\left(1+\tau_{q o}{ }^{\prime \prime} p\right)} X_{q}
\end{aligned}
$$

Expressed in terms of axis current, (4) becomes 
$\left[\begin{array}{l}i_{d}{ }^{\prime} \\ i_{q}{ }^{\prime}\end{array}\right]=\frac{1}{(D e t)}\left[\begin{array}{cc}-\left(R_{a}+p X_{q}(p) / \omega_{0}\right) & -X_{q}(p) \\ X_{d}(p) & -\left(R_{a}+p X_{d}(p) / \omega_{0}\right)\end{array}\right]\left[\begin{array}{c}v_{d}{ }^{\prime} / p \\ v_{q}{ }^{\prime} / p\end{array}\right]=\left[\begin{array}{cc}-D D & -D Q \\ Q D & -Q Q\end{array}\right]\left[\begin{array}{c}v_{d}{ }^{\prime} \\ v_{q}{ }^{\prime}\end{array}\right]$

With determinant

$($ Det $)=\frac{\omega^{2}\left(R_{a}{ }^{2}+X_{q}(p) X_{d}(p)\right)+p \omega R_{a}\left(X_{q}(p)+X_{d}(p)\right)+p^{2} X_{q}(p) X_{d}(p)}{\omega^{2}}$

Components $D Q, D D, Q Q$ and $Q D$ can thus be defined as (9) to (12)

$D Q=\frac{-X_{q}(p)}{p \times(D e t)}$

$D D=\frac{-\left(R_{a}+p X_{q}(p) / \omega_{0}\right)}{p \times(\text { Det })}$

$Q Q=\frac{-\left(R_{a}+p X_{d}(p) / \omega_{0}\right)}{p \times(D e t)}$

$Q D=\frac{X_{d}(p)}{p \times(D e t)}$

Simplified time-domain expressions for the four current components for use in (7) are (13), (14), (15) and (16). These have been extracted from those defined by Adkins et al [8], and contain a number of simplifications [22]. The equations are considerably more accurate when used to describe machines larger than the test alternator, but nevertheless they give a useful indication of the current transients that occur. As can be seen these equations contain the $1-\cos (\omega t)$ and $\sin (\omega t)$ components from Section 2.

$$
\begin{aligned}
& -v_{q}[D Q]=-v_{q}\left[\frac{1}{X_{d}}+\left(\frac{1}{X_{d}^{\prime}}-\frac{1}{X_{d}}\right) \exp \left(\frac{-t}{\tau_{d}^{\prime}}\right)+\left(\frac{1}{X_{d}^{\prime \prime}}-\frac{1}{X_{d}{ }^{\prime}}\right) \exp \left(\frac{-t}{\tau_{d}^{\prime \prime}}\right)-\frac{1}{X_{d}^{\prime \prime}} \exp \left(\frac{-t}{\tau_{a}}\right) \cos \left(\omega_{0} t\right)\right] \\
& -v_{d}[D D]=-v_{d}\left[\frac{1}{X_{d}^{\prime \prime}} \exp \left(\frac{-t}{\tau_{a}}\right) \sin \left(\omega_{0} t\right)\right] \\
& -v_{q}[Q Q]=-v_{q}\left[\frac{1}{X_{q}^{\prime \prime}} \exp \left(\frac{-t}{\tau_{a}}\right) \sin \left(\omega_{0} t\right)\right] \\
& +v_{d}[Q D]=v_{d}\left[\frac{1}{X_{q}}+\left(\frac{1}{X_{q}^{\prime \prime}}-\frac{1}{X_{q}}\right) \exp \left(\frac{-t}{\tau_{q}^{\prime \prime}}\right)-\frac{1}{X_{q}^{\prime \prime}} \exp \left(\frac{-t}{\tau_{a}}\right) \cos \left(\omega_{0} t\right)\right]
\end{aligned}
$$


The simplified time domain equation describing field current caused by a $v_{q}$ shift, $F Q$, as derived in [9] is shown in (17) and (18). $I_{f u}$ is the field current that produces 1.0 per unit terminal voltage in the unloaded machine. A similar equation (19) can be obtained for $v_{d}$ shift, $F D$.

$$
\begin{aligned}
& I_{f}=I_{f 0}-I_{f u}\left(\frac{X_{d}-X_{d}{ }^{\prime}}{X_{d}{ }^{\prime}}\right)\left\{v_{q(p . u .)}[F D]+v_{d(p . u .)}[F Q]\right\} \\
& v_{q(p . u .)}[F Q]=v_{q(p . u .)}\left[\exp \left(\frac{-t}{\tau_{d}{ }^{\prime}}\right)-\left(1-\frac{\tau_{k d}}{\tau_{d}{ }^{\prime \prime}}\right) \exp \left(\frac{-t}{\tau_{d}{ }^{\prime \prime}}\right)-\frac{\tau_{k d}}{\tau_{d}{ }^{\prime \prime}} \exp \left(\frac{-t}{\tau_{a}}\right) \cos \left(\omega_{0} t\right)\right] \\
& v_{d(p . u .)}[F D]=v_{d(p . u .)}\left[\frac{\tau_{k d}}{\tau_{d}{ }^{\prime \prime}} \exp \left(\frac{-t}{\tau_{a}}\right) \sin \left(\omega_{0} t\right)\right]
\end{aligned}
$$




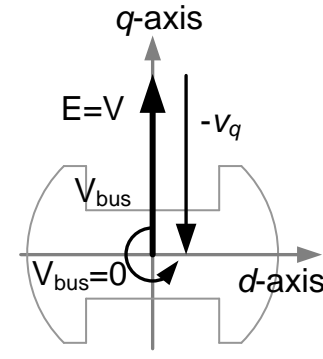

(a)

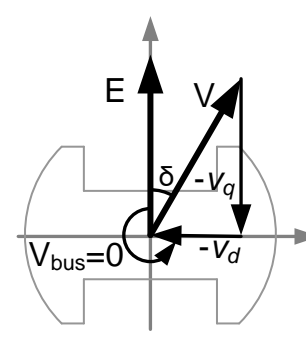

(b)

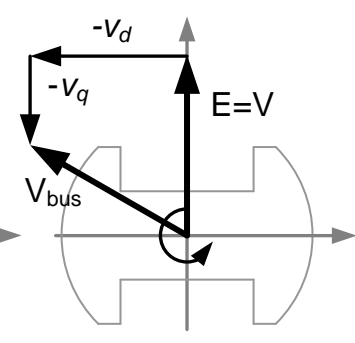

(c)

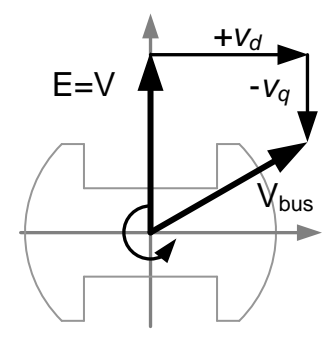

(d)

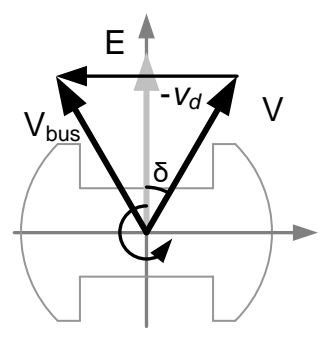

(e)

Figure 1 Sudden changes in voltage for different events

a) Sudden short-circuit of unloaded machine

b) Sudden short-circuit of loaded machine, $30^{\circ}$ load angle

c) Lagging $60^{\circ}$ out-of-phase synchronisation, unloaded

d) Leading $60^{\circ}$ out-of-phase synchronisation, unloaded

e) Lagging $60^{\circ}$ out-of-phase synchronisation, $30^{\circ}$ load angle 

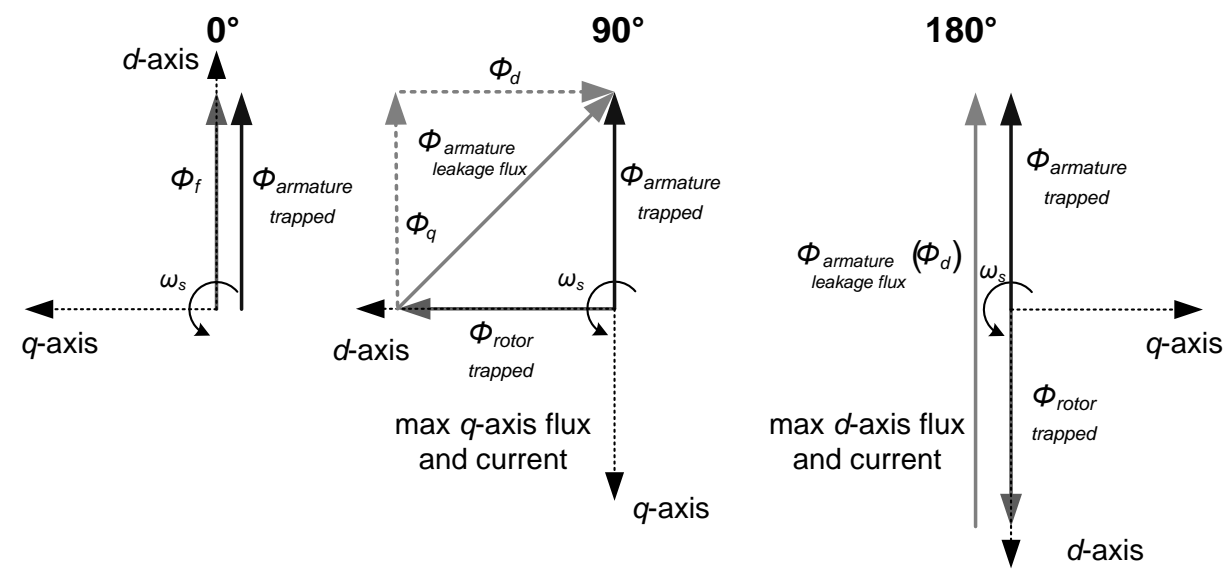

(a)

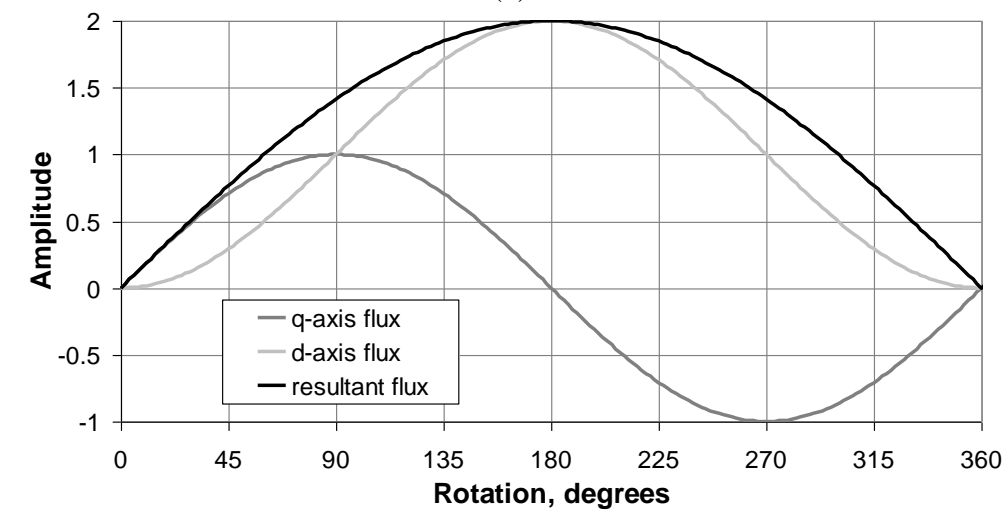

(b)

Figure 2

a) Components of flux following a $q$-axis voltage shift at $0^{\circ}, 90^{\circ}$ and $180^{\circ}$ rotation (anticlockwise rotation) b) Amplitude of $q$-axis, $d$-axis and resultant flux versus rotor rotation 


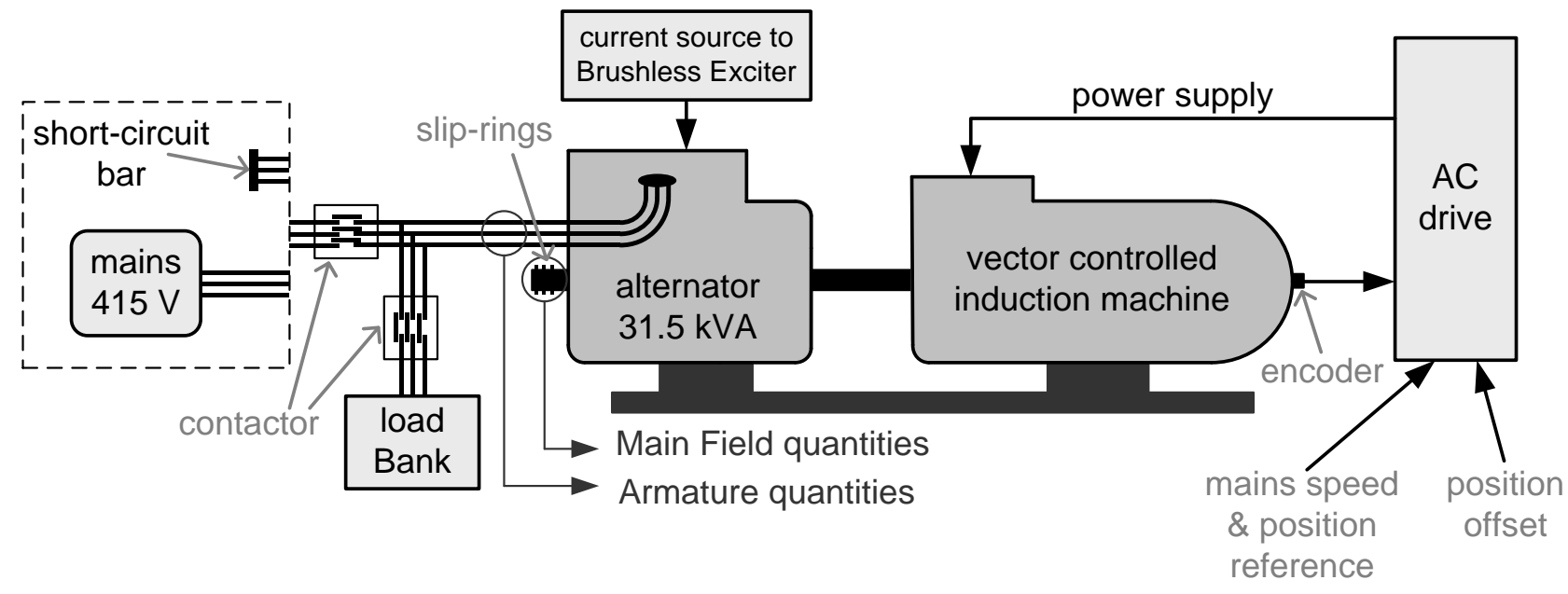

Figure 3 Experimental test-bed for $31.5 \mathrm{kVA}$ alternator 


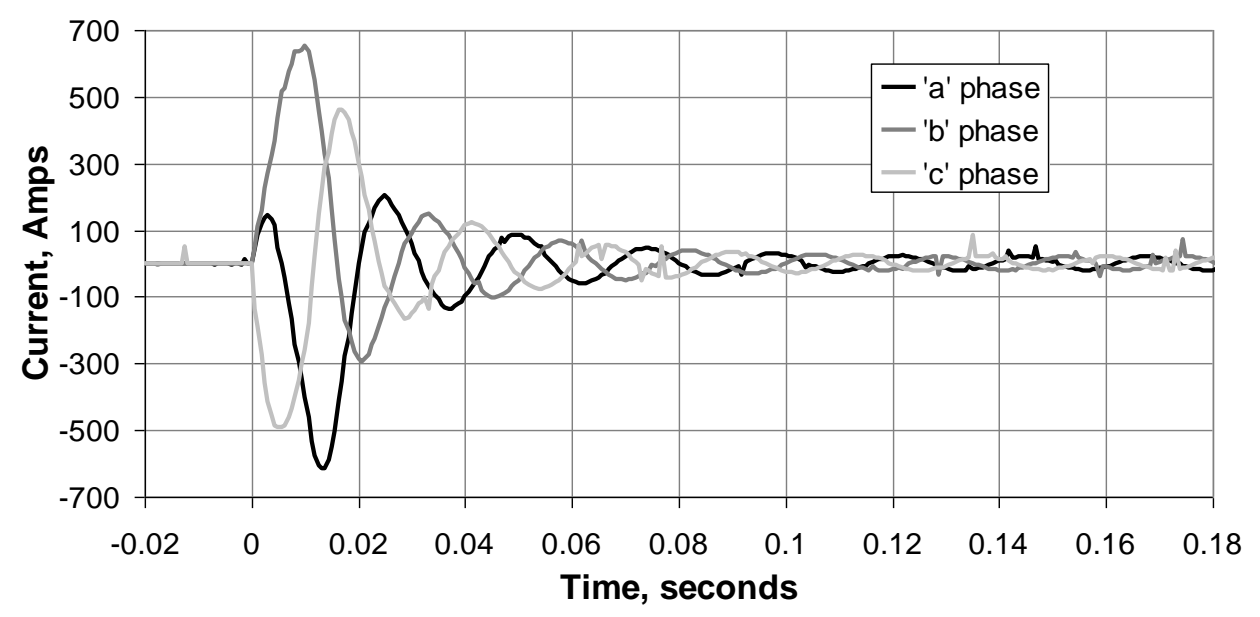

(a)

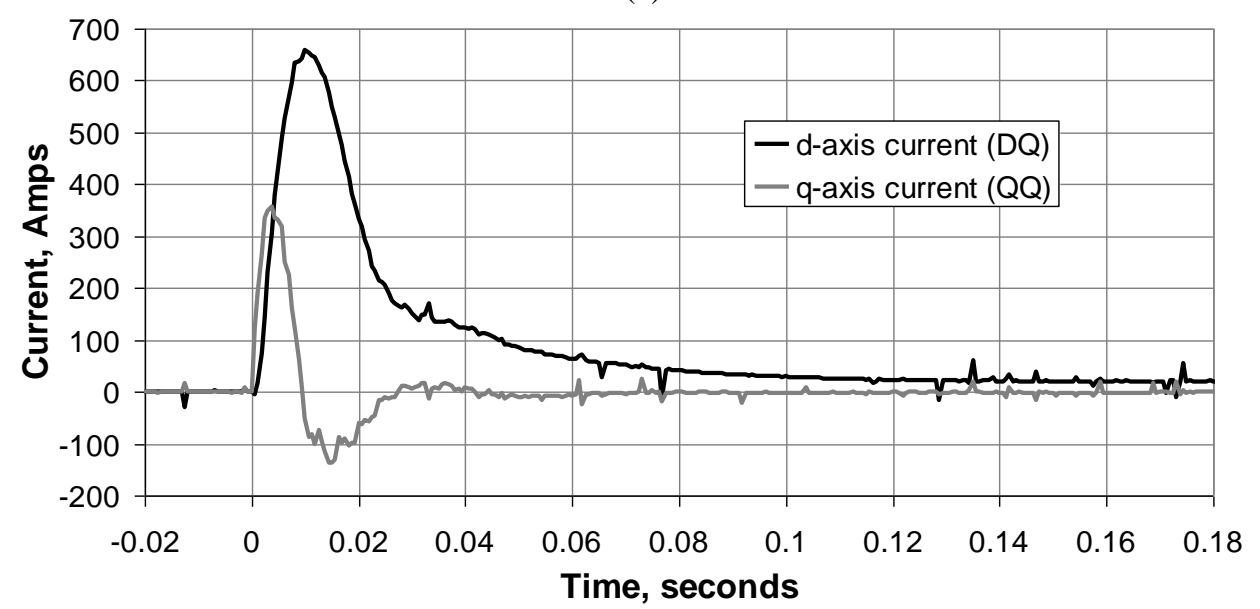

(b)

Figure 4 sudden three-phase short-circuit of $31.5 \mathrm{kVA}$ alternator

a) $a, b$ and $c$ phase currents

b) $d$-axis and $q$-axis armature currents 


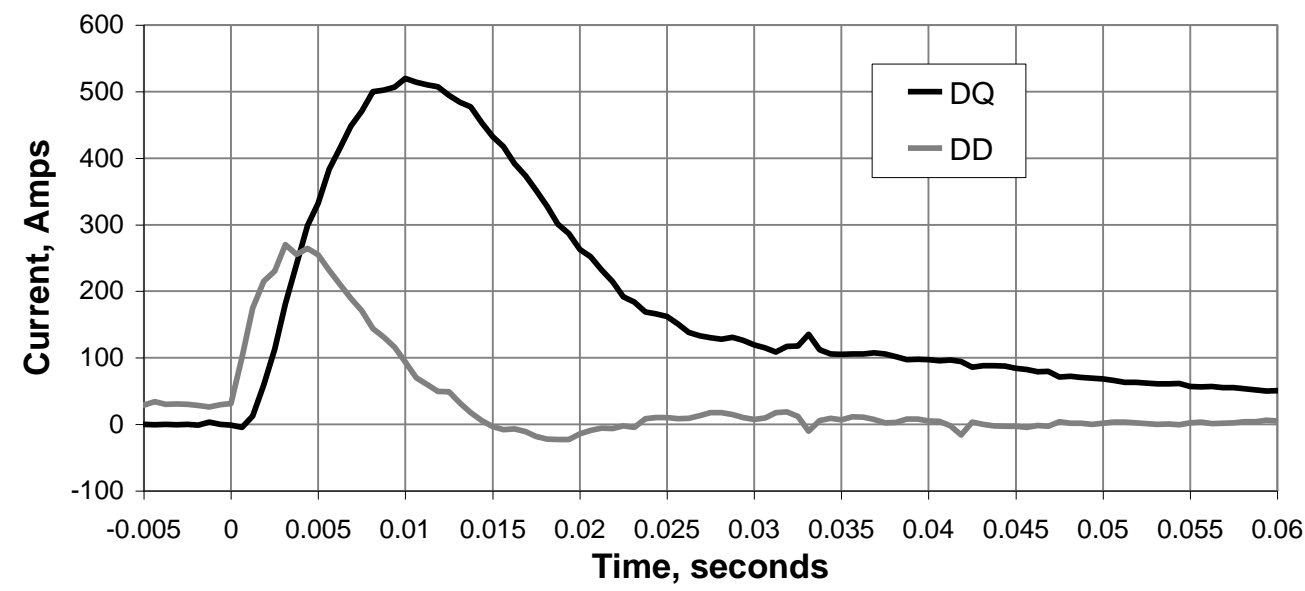

(a)

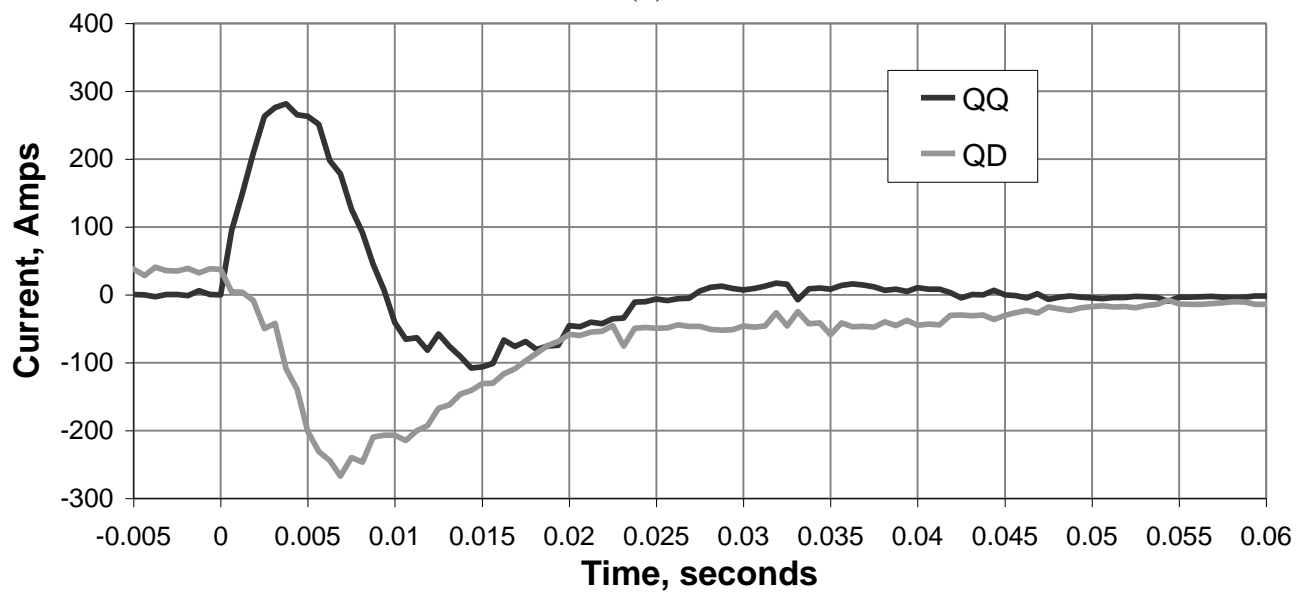

(b)

Figure 5 Current components of a loaded short-circuit of $31.5 \mathrm{kVA}$ machine at $38^{\circ}$ load angle a) $d$-axis current components, $D Q$ and $D D$

b) $q$-axis current components, $Q Q$ and $Q D$ 


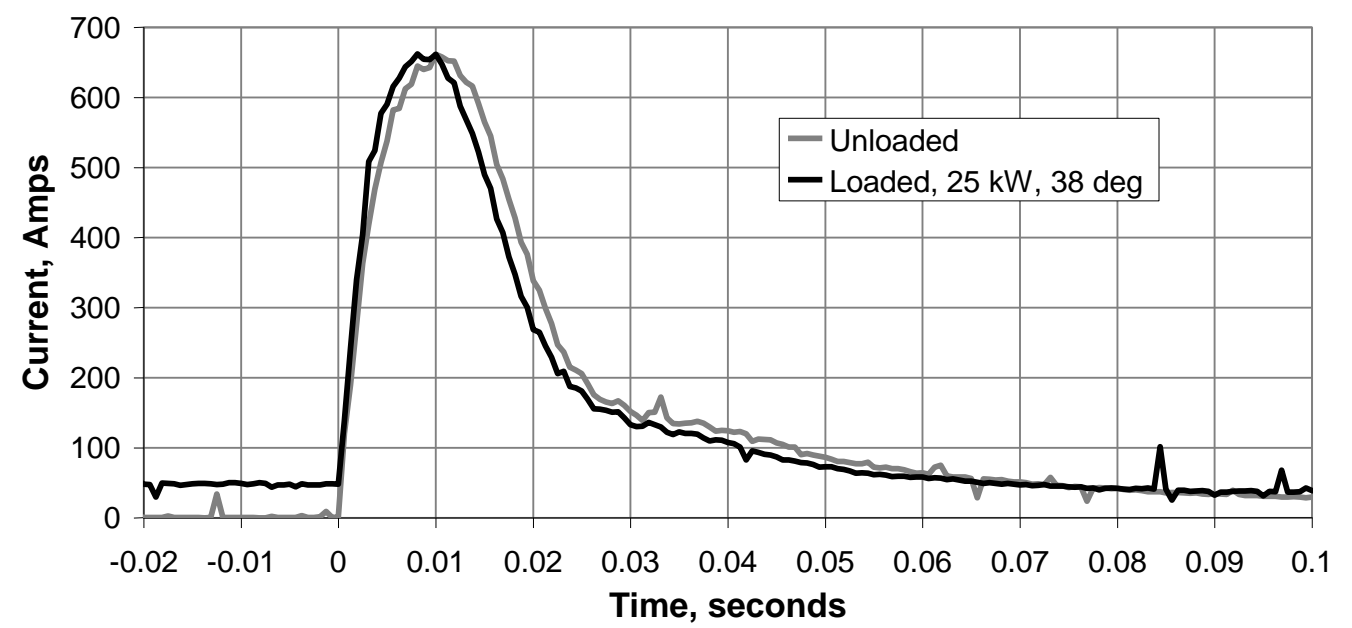

(a)

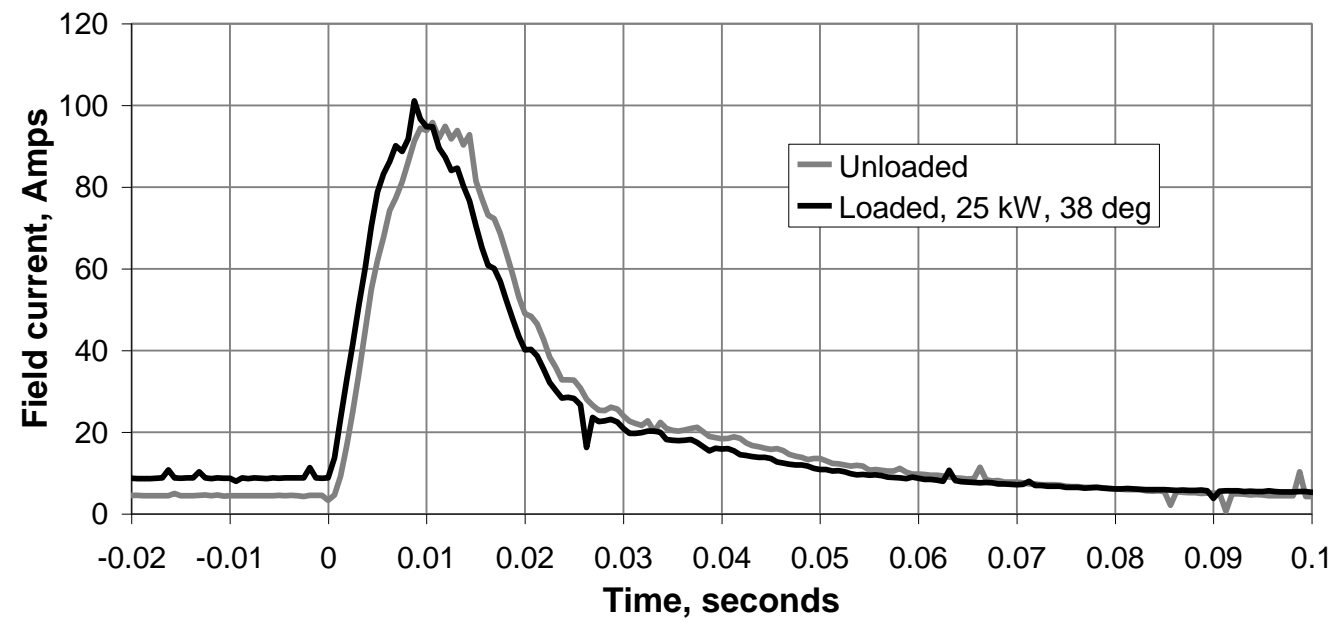

(b)

Figure 6 Comparison of current transients for unloaded and $38^{\circ}$ load angle sudden three-phase short-circuits a) Resultant armature current

b) Field Current 


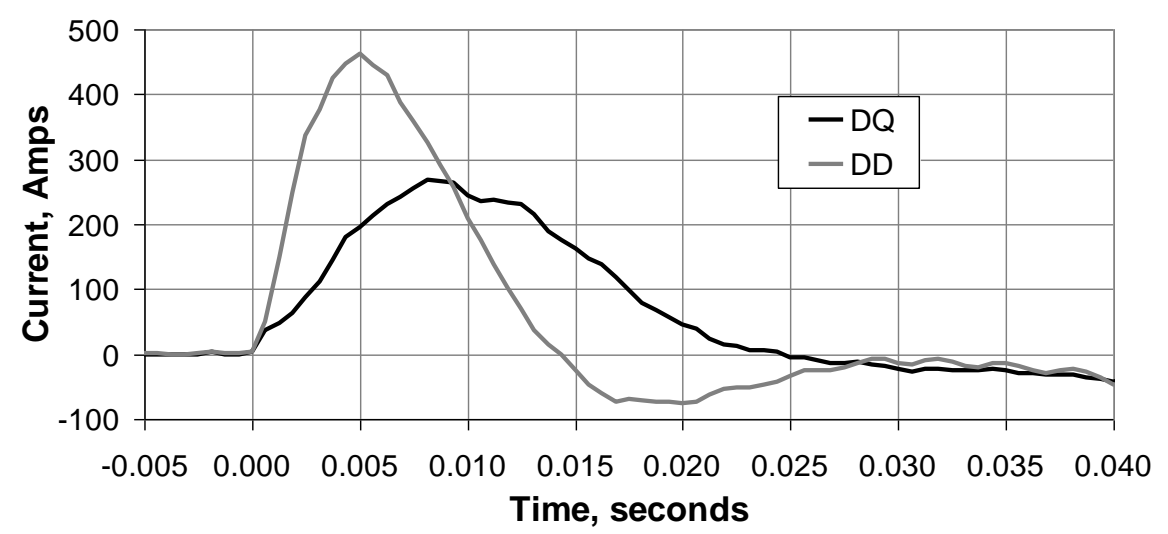

(a)

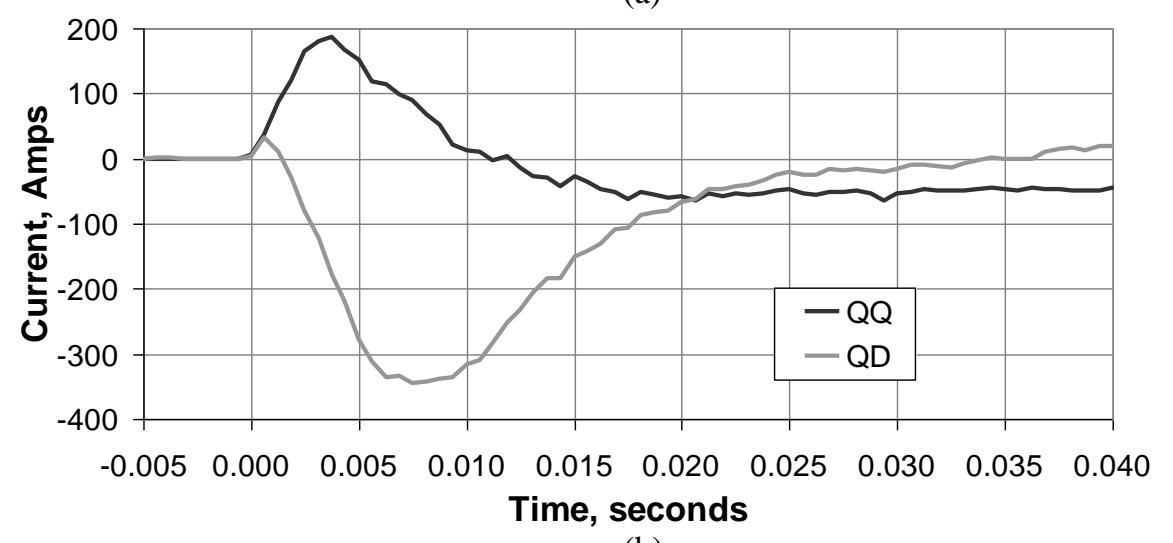

(b)

Figure 7 Current components of a $60^{\circ}$ out-of-phase synchronisation a) $d$-axis current components, $D Q$ and $D D$

b) $q$-axis current components, $Q Q$ and $Q D$ 


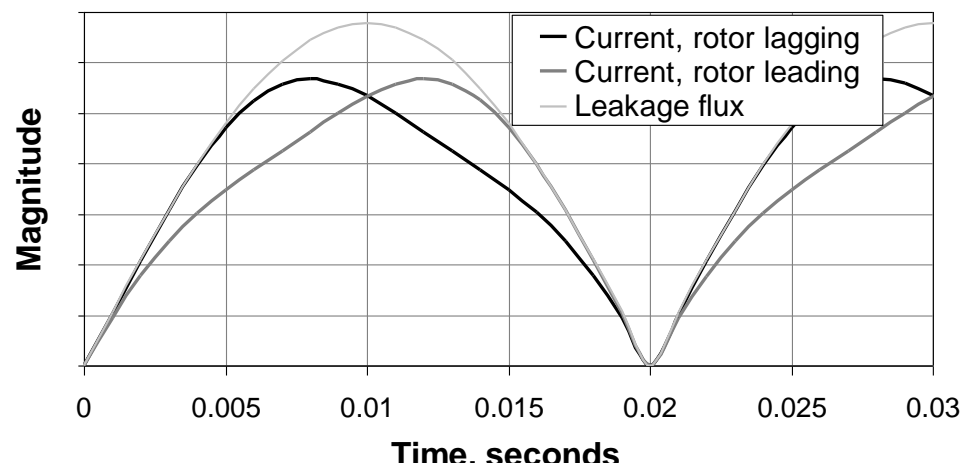

Time, seconds

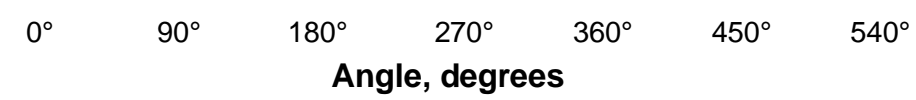

(a)

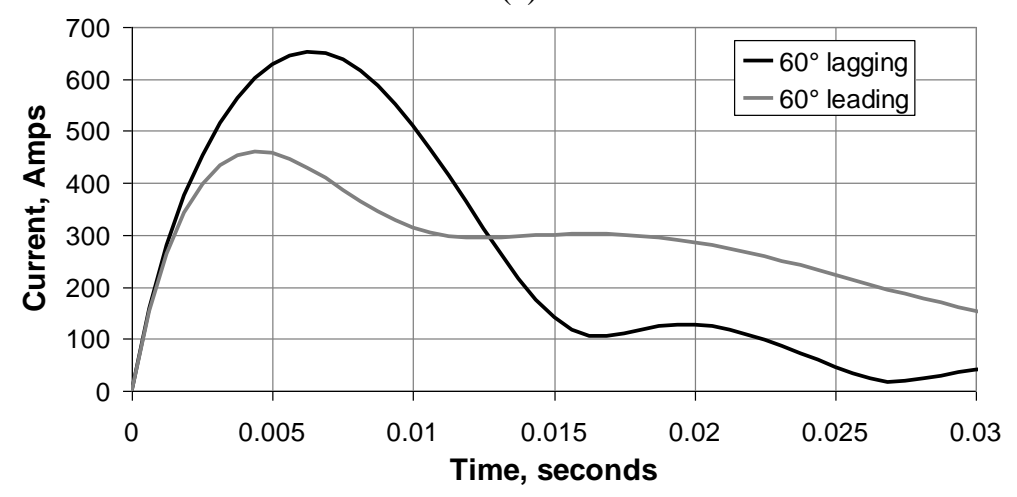

(b)

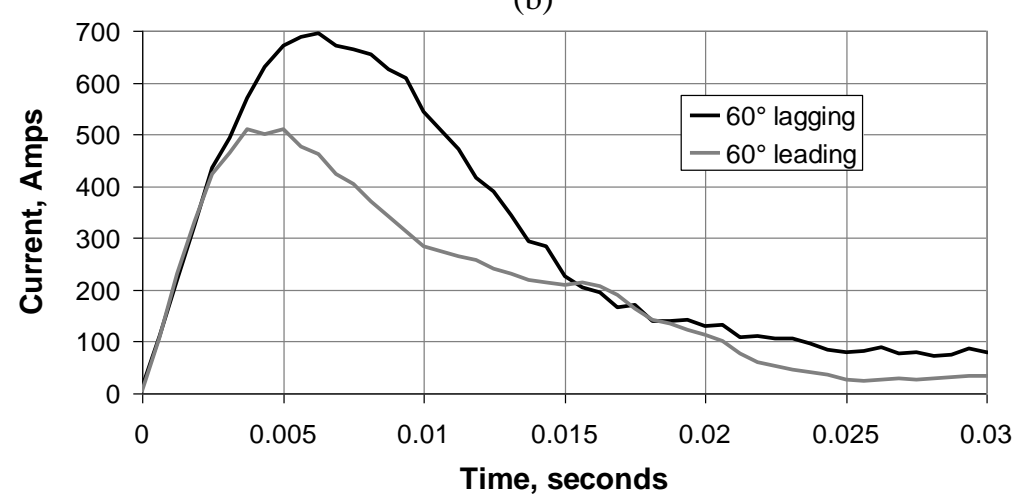

(c)

Figure 8 Time of peak current in salient-pole alternator following $60^{\circ}$ synchronisations to $50 \mathrm{~Hz}$ system a) Theoretical peak resultant armature current, ignoring decay

b) Simulation of peak resultant armature current, equation (7) in Appendix

c) Experimentally obtained peak resultant armature current 


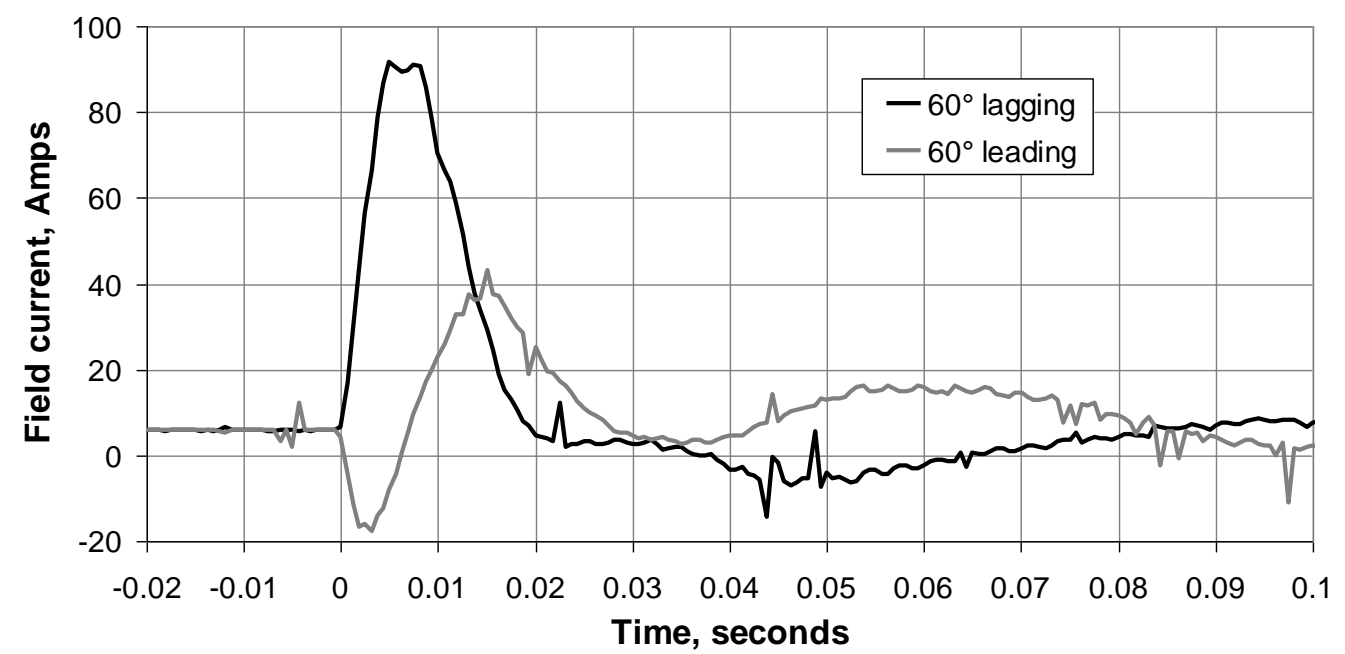

Figure 9 Field current during rotor lagging and rotor leading synchronisations at $60^{\circ}$ 


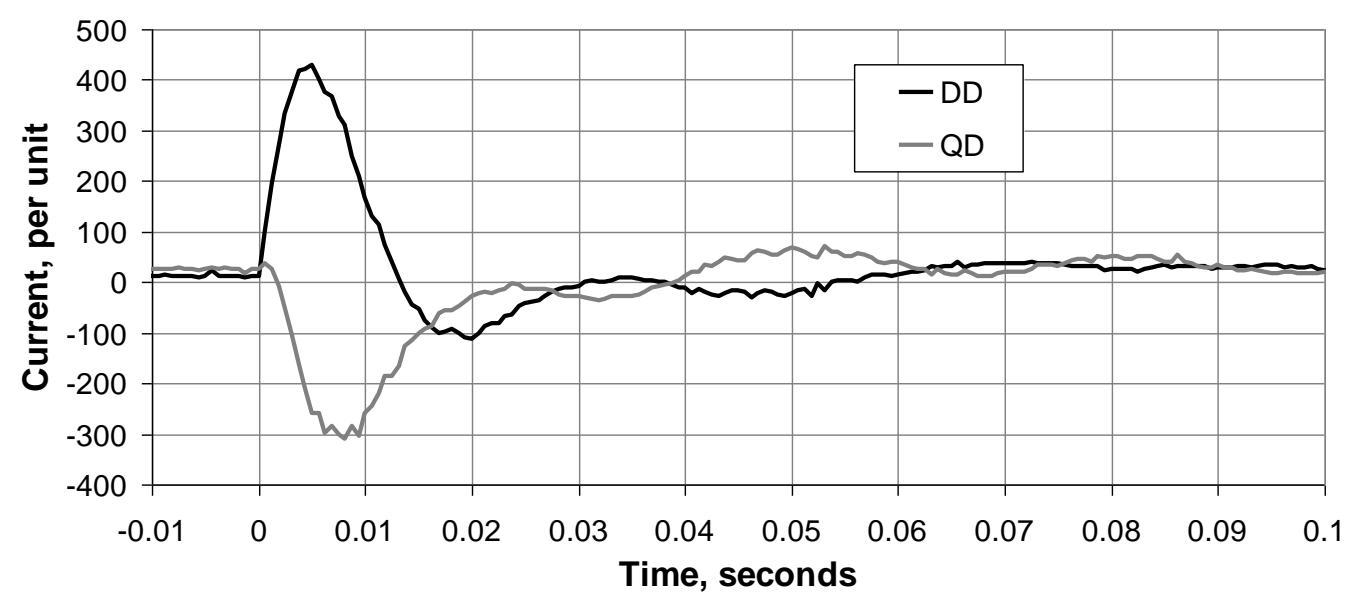

(a)

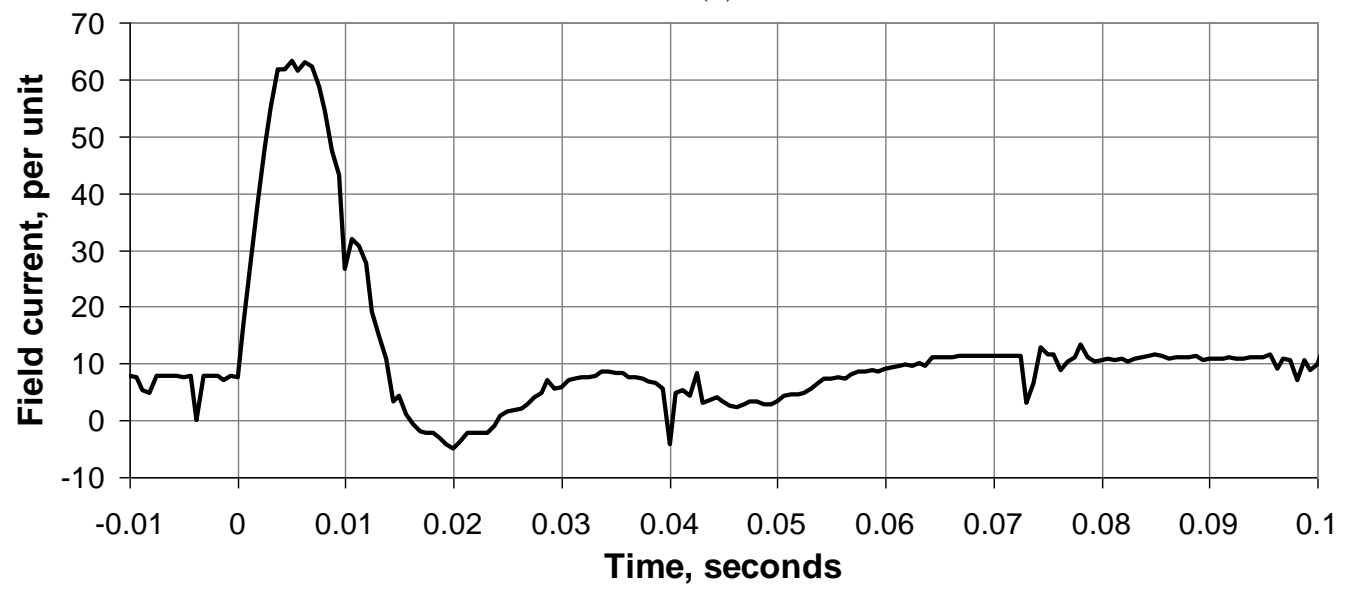

(b)

Figure 10 Events with only $v_{d}$ shift -0.84 , level excited $50^{\circ}$ synchronisation with $22^{\circ}$ load angle a) $d$-axis and $q$-axis armature current

b) Field Current 


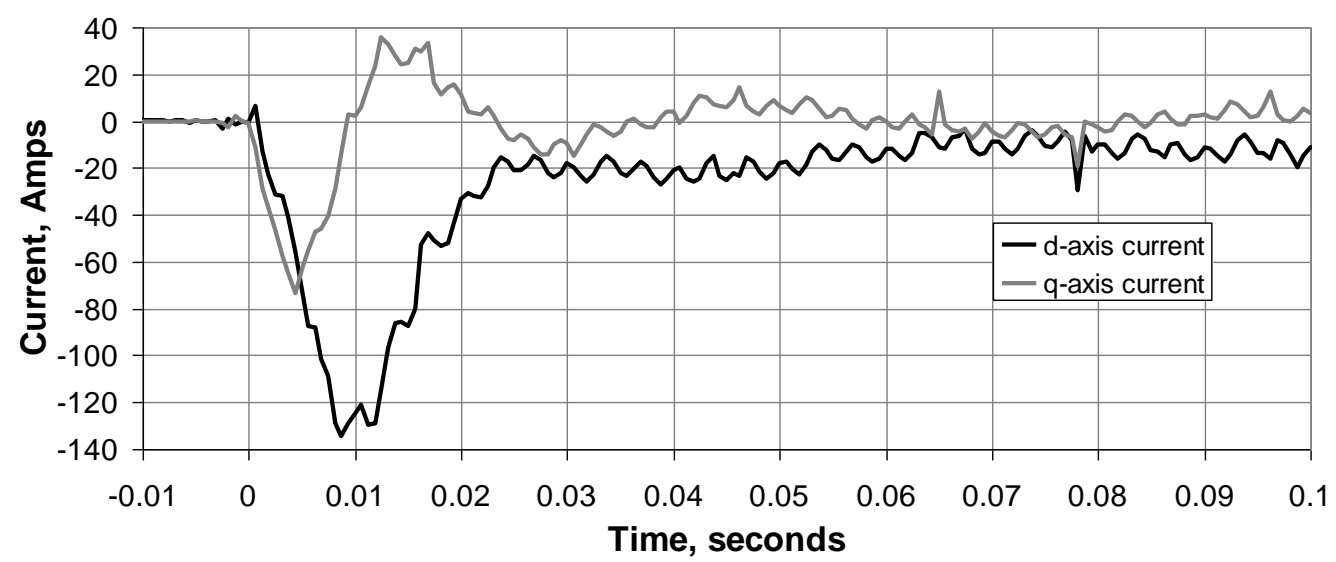

(a)

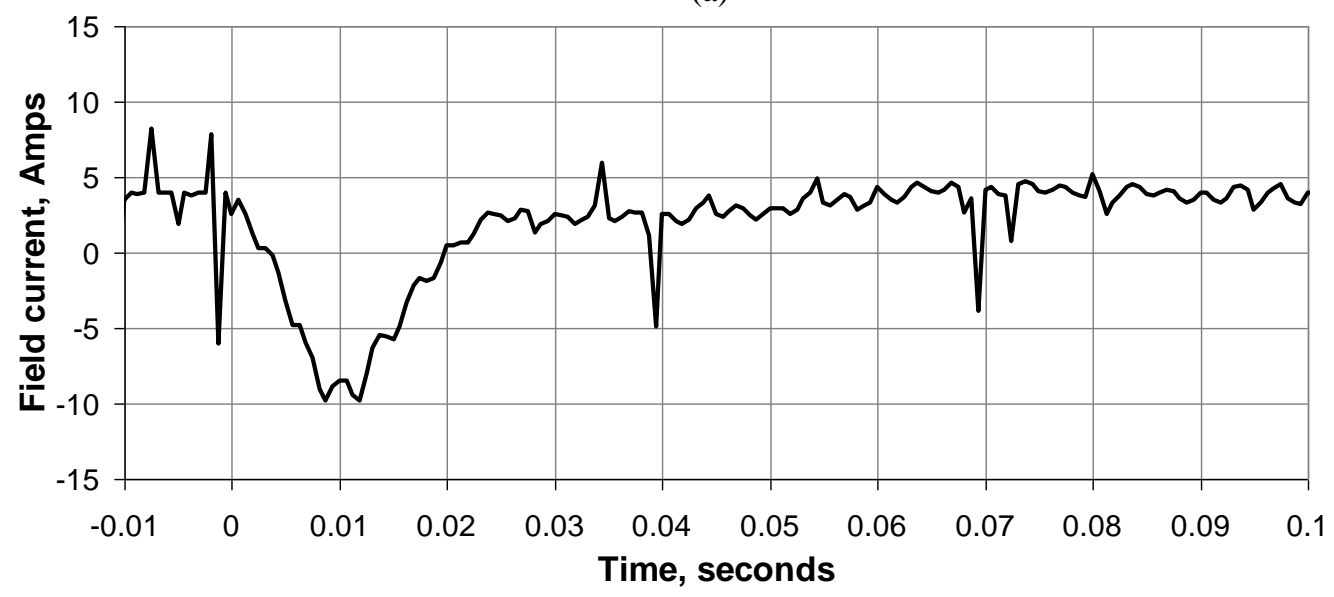

(b)

Figure 11 Current transients for $0^{\circ}$ gird synchronisation of an under-excited unloaded machine a) $d$-axis and $q$-axis armature current b) Field current 


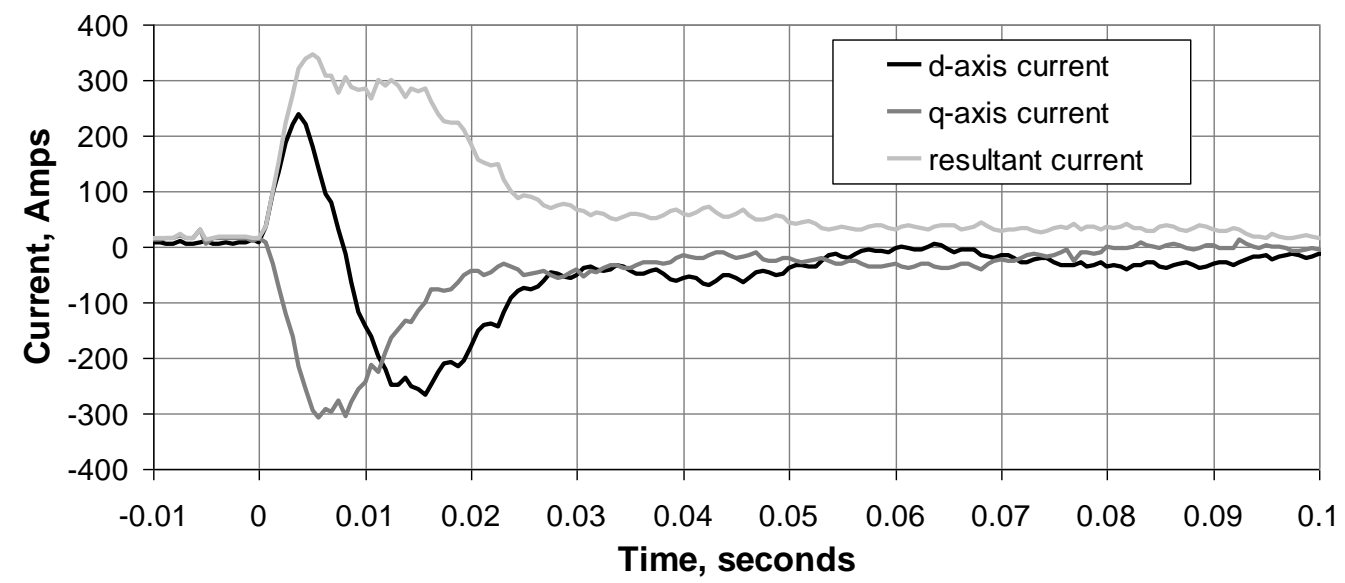

(a)

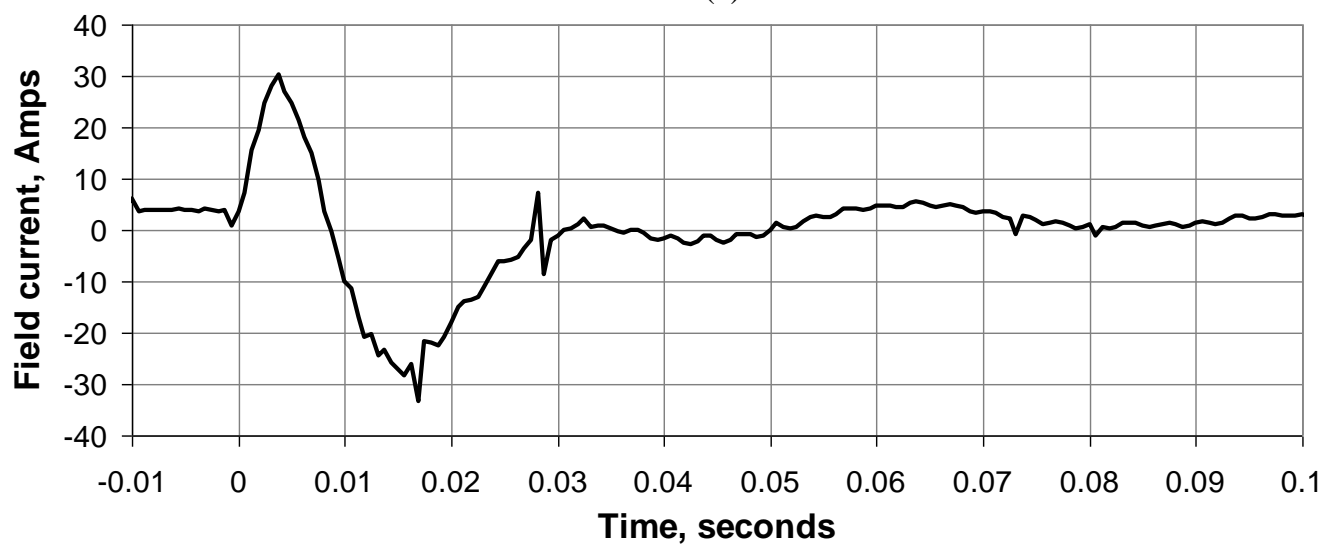

(b)

Figure 12 Event with $v_{q}=+0.37 \mathrm{pu}$ and $v_{d}=-0.68 \mathrm{pu}$

a) $d$-axis and $q$-axis armature current

b) Field current 